\title{
The many flavors of "yes" Libraries, collaboration, and improv
}

\author{
When I was starting out . . . doing \\ improvisational theatre . . there was \\ really only one rule I was taught about \\ improv. That was, "yes-and." In this \\ case, "yes-and" is a verb. To "yes-and." \\ I yes-and, you yes-and, be, she or it \\ yes-ands. And yes-anding means that \\ when you go onstage to improvise a \\ scene with no script, you have no idea \\ what's going to happen, maybe with \\ someone you've never met before. . . . \\ And because, by following each other's \\ lead, neither of you are really in con- \\ trol. It's more of a mutual discovery \\ than a solo adventure. What happens \\ in a scene is often as much a surprise \\ to you as it is to the audience. \\ —Stephen Colbert, Commencement Ad- \\ dress to Knox College ${ }^{1}$
}

D evelop Strategic Partnerships" may as well be a mandate at most institutions of higher education these days. But while it is something we librarians have always done, it would be disingenuous to claim that it's ever been easy. Interdisciplinary collaboration means that academic librarians must draw upon the functional and technological expertise of staff who are not always public facing. Some of us know how to teach, others how to code. Failing to account for the interpersonal tools needed to bridge these domains simply creates additional barriers to collaboration.

Our own working relationships have benefitted immensely from the application of techniques from an unlikely source: improvisational comedy. ${ }^{2}$ We use these tools to navigate a shifting academic landscape where priorities are constantly being revised, rewritten, and thrown out the door.

\section{The concept of affirmation}

Early in 2015, we began developing a workshop for librarians that explored some of the fundamental themes of improvisation, drawing upon our own backgrounds in speech, theater, and improv. We saw a need for this workshop as we were both being asked to negotiate the messy, shifting boundaries of digital scholarship and instruction. ${ }^{3}$ It turned out to be a loose, safe space for librarians of all stripes to explore and experiment. Like any good improv scene, every workshop has unearthed different questions and themes, as we start from one place and end up in another. Nevertheless we have found that one of the most essential tenets of improv-the concept of affirmation - surfaces time and again.

Whether on stage or in the library, affirmative environments share a few key characteristics. Individuals who commit to affirmation drop their egos and listen without judgment

\footnotetext{
Kate Dohe is digital programs and initiatives manager at the University of Maryland Libraries'McKeldin Library, email: katedohe@umd.edu, and Erin Pappas is Arts and Humanities librarian for Alderman Library at the University of Virginia Libraries, email: erin.pappas@ virginia.edu.
}

(c) 2017 Kate Dohe and Erin Pappas 
to the ideas of everyone in their ensemble, regardless of rank or clout. They recognize and promote shared expertise and co-creation over individual recognition. They produce ideas and deliver results that are more than the sum of their discrete parts. Such groups often have momentum, and as a result attract more partners and opportunities to tackle complex problems. Most importantly of all, affirmation engenders trust and strengthened relationships between team members. When every person is committed to making his or her teammates look good, then great ideas are allowed to flourish and develop into great initiatives.

The first step in creating an environment of affirmation is getting people comfortable with saying yes unconditionally, so that yes becomes more reflexive than no. Our workshop participants have told us that it's incredibly freeing to be in an environment where agreement is the norm and they can throw out any idea that occurs to them without fear. Ideas suddenly flow fast and free, and when each participant enthusiastically latches on to the ideas of others, new perspectives and interpretations are revealed. Colleagues tell us they suddenly gain new insight into the experiences and contributions of others through these exercises, and thus reflect upon the value of such offerings without biases. We ask our participants what it means to say yes without hesitation, and to compare that to their everyday work environments. Perhaps unsurprisingly, most of them don't hear agreement all that often.

Yes is a wonderful beginning and critical first step, but we cannot stop there. In work as in improv, a person cannot blithely agree with every idea he or she encounters without considering it. On stage, an improv player must pay careful attention to the context and actions of others when an idea is offered up, so that their reaction is furthering the scene and in tune with the environment on stage. This is why the improv mantra is "yes, and ..." rather than yes all by itself.

Of course, we must operate within real constraints of time, funding, and mission.
In academic libraries, we keenly feel these constraints every day. We rush from project meetings to consultations to one-shot sessions, review budgets for yet another round of cuts, and balance the competing demands that come with serving a constituency as vast as a "campus community." There is a wealth of literature available on what such pressures can do to individuals within libraries-anxiety, fear, and defensiveness are merely the tip of iceberg. When left unchecked, these competing demands can lead to burnout, toxic workplaces, and devaluation of library services by university administration. Many of us are professionally driven to say yes, to be helpful, even within challenging environments. How many times do we say yes simply to avoid the messy conversation that a no would entail? However, there are many ways of saying yes, and not all of them are supportive or advance ideas in a meaningful way.

Yes can come burdened with what improv practitioners refer to as stop words: but, however, whatever, because. These variations of yes can be destructive rather than constructive. Consider these common examples:

- "Yes, but ..."-This yes is a no in disguise. The speaker uses a veneer of supportiveness to dismiss the idea offered, while avoiding outright conflict.

- "Yes, because ..."-This yes lets the speaker comment on the action (or repeat the idea outright) and claim credit for participating, but shifts the burden of advancing the idea to others in the room.

- "Yes, whatever ..."-This yes is the calling card of groupthink, when others in the room protect their egos by disengaging, and letting a dominant voice take charge.

Institutions can have extremely long memories, and past experiences can condition us to have a perpetual fear of failure. Quick. Think of an idea you proposed that was met with one of these false yeses: "Yes, we tried that idea $\{\mathrm{x}\}$ years ago, but it didn't work." You can probably think of several without trying too hard. The past is always nearer for those who have been in the same 
place for a while, and institutional knowledge can be both a blessing and a curse. In these instances it seems altogether easier to bring up those stop words and continue on with business as usual.

Improv yes, however, is always followed by and. . . Think back to what Stephen Colbert said about the importance of "yes, and ..." where the and represents the next piece, the next brick in making the house. Yes-and is the mantra because it doesn't leave your team hanging with an idea. It moves the idea to the next stage, and by building on, makes it better. And is the essential mechanism of co-creation. This happens when many participants contribute to an idea. In bringing their bricks to build a house, all can take shared ownership of the end result. And is a natural check to domineering, narrowly focused, top-down mandates. For one, it prevents any one individual from directing or dictating, as more ideas lead in unexpected directions. Within this space, the concept of "mistakes" is irrelevant, because every group member accepts each contribution as the shared property of the group, and develops it further instead of rejecting it out of hand.

Consider this hypothetical scenario. A group of library staff come together to choose a new intranet. The first person suggests a new product that is very expensive, and it is dismissed by the ranking department head in the group immediately as being too expensive. The second person suggests an established product that the library demoed several years ago, and a more senior staff member says that it didn't work then, so it probably wouldn't work now. The third person proclaims that keeping a bunch of Word files on the shared drive is fine with him, and the library doesn't even need an intranet. No one in the room responds to that statement, and after several moments of silence, the department head suggests a product that she saw presented at a conference by the library's aspirational peers, and announces if it works for them, it will work for anyone.
The team agrees without much discussion or enthusiasm, and the project stalls as it "sits on the back burner," while everyone becomes frustrated that no one seems motivated to work on the project.

If that scenario is triggering Meeting PTSD, try re-imagining it when everyone in the room plays by the rules of "yes, and ." The first suggestion for a product that is very expensive is put forth, and the department head responds that yes, that is a very good product and that there may be a way to implement the most desired features within the current budget. Another person chimes in that yes, a free product supports many of those essential features, and could be demoed easily. Someone else contributes that yes, that product is easy to demo, the library had done so years ago, and that there may be existing documentation from the last evaluation. Others volunteer to investigate the product, suggest other unexpected products that meet the feature requirements, help secure demos, and organize library units for testing and feedback. Suddenly, this is a group with momentum, action, and high levels of engagement, creatively pursuing a solution in pursuit of a common goal.

In our own respective roles as a liaison librarian and manager of digital programs, we find many ways to apply these concepts of affirmation while advancing the missions of our libraries, though each of us must frequently work with different groups. The techniques vary when one is collaborating with students and faculty versus managers and employees.

For instance, one of the first things a new public-facing librarian must learn is the importance of the reference interview which is, in and of itself, predicating on asking a series of questions that are yes-oriented. In its ideal form, the reference transaction or research consultation is about drawing out the thread of a workable idea from what may be a fuzzy, overly ambitious, or unrealistic project. Learning how to say yes while moving an idea forward, shaping it into something manageable, is a skill that 
can be learned, honed, and applied beyond the reference encounter.

If we turn to the case of digital initiatives, there the work is much more costly and highstakes. The answer to every request obviously cannot be a blank check, open-ended resourcing, or infinite staff. To give one recent example, during a planning meeting the manager asked everyone on the team to suggest projects for the upcoming year. During discussion, each idea was evaluated from a team perspective, contributing additional information to shape the project and how it might be accomplished. Some less-developed projects, including some proposed by the manager, were fully explored and ultimately tabled in favor of other ideas. When setting priorities, managing workloads, and assessing resources for a team, supporting an affirmative, hierarchy-free environment is key to building the rapport needed for honest evaluation of ideas.

When the authors were both working at the same institution, applying this technique worked out successfully on many occasions. We found it to our mutual benefit to say yes to one another using improv principles. To give one example of how this idea played out in practice, we turn to the following instance. During the summer, the liaison librarian received a request from one of her departments to create a video and text archive of student capstone presentations. This came with the caveat that students pursuing security clearances would have substantial concerns about the subsequent access and discoverability of such materials. She responded affirmatively ("yes") to see what might be possible without making any unfounded promises. The next step ("and?") was to approach the digital librarian about the project.

The digital librarian, in turn, carried the idea forward as being technologically manageable ("yes"). She expressed that she would need to consult with the stakeholders to assess their current systems ("and?"), as well as pulling in the scholarly communication librarian regarding the students' privacy concerns ("and?"). Working together, we devised a project to collect student videos and papers with the appropriate release form created by the scholarly communication librarian, placing them in our institutional repository according to each student's preferred access level.

\section{Final thoughts}

We close with a series of questions. Are you your own best collaborator? Are you a person you want to work with? What would you need to do to be the best person to work with, and what would you need to let go? If you can identify times you've said (or thought, or implied) "yes, but..." and "yeah, whatever," is that rooted in your own selfperception? Put another way, you can't fix your colleagues, but you can fix you.

Consciously look for places to say yes, and to your colleagues, and reflect critically on what that means in your work life. Sign up for an improv workshop if your city or town offers them. Learn what it means to be in that completely ego-free space, and you'll be pleasantly surprised at the results.

\section{Notes}

1. Stephen Colbert, "Commencement Address," transcript of remarks to graduating seniors at Knox College in Galesburg, Illinois, June 3, 2006, http://departments.knox.edu /newsarchive/news_events/2006/x12547. html.

2. Matt Besser, Ian Roberts, Matt Walsh, and Joe Wengert, The Upright Citizens Brigade Comedy Improvisation Manual (New York: Comedy Council of Nicea LLC, 2013); Charna Halpern, Del Close, and Kim "Howard" Johnson, Truth in Comedy: The Manual of Improvisation (Colorado Springs, Colorado: Meriwether Publishing, 1994); Anne Libera, The Second City Almanac of Improvisation (Evanston: Northwestern University Press, 2004); Amy Poehler, Yes Please (New York: Dey Street, 2014).

3. Eamon C. Tewell. "What Stand-up Comedians Teach us about Library Instruction: Four Lessons for the Classroom," CREL News 75 (January 2014): 28-30. $\approx 2$ 